\title{
Can Attachment Theory Help Explain the Relationship Between Childhood Adversity and Psychosis?
}

\author{
John Read and Andrew Gumley
}

\section{Dominance of the medical model}

$\mathrm{F}$ or several decades our efforts to understand the causes of human distress, despair, and confusion have been impeded by the dominance of a simplistic, reductionist paradigm interested primarily or exclusively in genes and neurotransmitters (Bentall, 2003; Read, Mosher, \& Bentall, 2004). This 'medical model' has been enthusiastically supported by the pharmaceutical industry, which has much to gain from promulgating an ideology that minimizes psycho-social causes (Mosher, Gosden, \& Beder, 2004; Read, 2008). Although the dominance of this model pervades all categories of psychiatric diagnoses, nowhere has it been stronger or more damaging than in the field of psychosis. Since the invention of the supposed illness 'schizophrenia' a century ago (Bentall, 2003; Read, 2004a), millions of people worldwide have been condemned to the pessimistic, self-fulfilling, and stigmatizing belief that they are suffering from some kind of irreversible brain disease. This disease, which has wrongly been presented as largely genetically determined, supposedly has little or nothing to do with one's life history or circumstances.

It is important to realize that the public, all over the world, have never accepted the illness model of mental health problems in general, or of 'schizophrenia' in particular. In virtually every country where surveys have been conducted, the public believes that madness is primarily a reaction to bad things happening to people rather than bio-genetically based illnesses (Angermeyer \& Dietrich, 2006; Read, 2007). Everywhere 'schizophrenia' is seen by the public (including patients and family members) to be caused by poverty, isolation, family problems, child abuse and neglect more than by faulty genes or brains. This is despite millions of dollars, often donated by drug companies, 
being spent 'educating' the public that 'mental illness is an illness like any other'. Studies repeatedly show, however, that the illness paradigm makes attitudes worse (Read, Haslam, Sayce, \& Davies, 2006).

Fears concerning 'parental blaming' have inhibited a productive and scientific exploration of the developmental and interpersonal roots of psychosis, including a compassionate understanding of the importance of early parental and peer attachments in the evolution of resilience and vulnerability. Furthermore, schizophrenia has long been regarded as a non-affective psychosis. This distinction between schizophrenia and affective psychoses is reinforced by neurodevelopmental models of schizophrenia that have evolved in isolation from developmental theories of interpersonal functioning and affect regulation. Bentall, Fernyhough, Morrison, Lewis, and Corcoran (2007) have also criticized neurodevelopmental models for the lack of specificity of key variables in predicting schizophrenia, such as delayed developmental milestones, season of birth, maternal starvation, and ventricular enlargement. Garfield (1995), in contrast with the mainstream view of schizophrenia as a non-affective psychosis, advanced a strong argument in support of the centrality of affect in the psychotherapy of this disorder. Gumley, White, and Power (1999) argued for the centrality of emotion regulation in understanding the development and course of psychosis. More recently, Birchwood (2003) has argued that emotion dysfunction is intrinsic to schizophrenia and can be best understood within the context of social developmental pathways. Gumley and Schwannauer (2006) have argued that schizophrenia and, indeed, other psychoses are fundamentally disorders characterized by affect dysregulation and that such an account can be sustained in the framework of attachment theory.

\section{The psychosocial causes of 'schizophrenia'}

Many recent studies demonstrate that the public are right to assume that psychosocial factors play a major role in the causation of madness. They are the same factors that are causal for most other mental health problems. Many of them are factors that are relevant to the formation of secure attachment.

\section{Poverty, urban living, and ethnicity}

Poverty, for example, has repeatedly been found, in a range of countries, to be even more strongly related to 'schizophrenia' and psychosis than to other disorders (Read, 2004b). For example a British study found that deprived children are four times more likely to develop 'non-schizophrenic' disorders but eight times more likely to grow up to be 'schizophrenic' than non-deprived children (Harrison, Gunnell, Glazebrook, Page, \& Kwiecinski, 2001). Even among children with no family history of psychosis the deprived children were 
seven times more likely to develop schizophrenia, demonstrating that you do not need a genetic predisposition to develop schizophrenia. Other studies confirm the influence of psychosocial factors in the absence of the supposed genetic predisposition to 'schizophrenia'. For example, the relationship between urban living and schizophrenia remains after controlling for family history of psychiatric disorder (Lewis, David, Andreassen, \& Allebeck, 1992; Pedersen \& Mortensen, 2001).

Ethnicity, too, is a very powerful predictor of 'schizophrenia'. This has been demonstrated in Australia, Belgium, Denmark, Germany, Greenland, the Netherlands, New Zealand, Israel, Sweden, the UK, and the USA (Read, 2004b). In Britain, incidence rates for schizophrenia are 3.6 times higher among all ethnic minority groups combined than among whites (King, Coker, Leavey, Hoare, \& Johnson-Sabine, 1994) and Afro-Caribbeans have been found to be as high as twelve times more likely to be diagnosed schizophrenic than white people (Harrison, Owens, Holton, Neilson, \& Boot, 1988). Although racist misdiagnoses are part of the explanation, there are environmental factors that consistently link ethnicity to schizophrenia, particularly racist discrimination, financial disadvantage, unemployment, parental loss, and social isolation (Bhugra, Leff, Mallett, \& Der, 1997; Janssen et al., 2003; Mallett, Leff, Bhugra, Pang, \& Zhao, 2002; Morgan et al., 2007).

\section{Child abuse and neglect}

After decades of ignoring the possibility of a relationship between adverse events in childhood and psychosis later in life (and often denigrating those who raised the possibility by accusing them of being 'family blaming'), numerous research studies have now established that child abuse and neglect are indeed a significant part of the complex aetiological jigsaw puzzle.

A recent review of forty-six studies of female inpatients and samples of predominantly psychotic female outpatients $(n=2604)$ calculated that $48 \%$ had been subjected to childhood sexual abuse (CSA) and $48 \%$ to childhood physical abuse (CPA). The majority (69\%) had been subjected to either CSA or CPA. The figures for men (thirty-one studies, $n=1536$ ) were CSA 28\%, CPA 50\%, CSA or CPA 59\% (Read, van Os, Morrison, \& Ross, 2005).

There is strong evidence that CSA and CPA are related to the symptoms of psychosis and 'schizophrenia', particularly hallucinations and paranoid delusions (Ross, Anderson, \& Clark, 1994; Hammersley, Dias, Todd, Bowen-Jones, Reilly, \& Bentall, 2003; Read, Argyle, Agar, \& Aderhold, 2003; Bebbington et al., 2004; Read, Goodman, Morrison, Ross, \& Aderhold, 2004; Whitfield, Dube, Felitti, \& Andra, 2005; Read \& Hammersley, 2006; Romme \& Escher, 2006; Spence, Mulholland, Lynch, McHugh, Dempster, \& Shannon, 2006; Murphy, Shevlin, \& Adamson, 2007; Shevlin, Dorahy, \& Adamson, 2007a,b). Recent 
large-scale general population studies controlling for possible mediating variables indicate that the relationship is a causal one, with a dose effect. For example, a prospective study of over 4,000 people in the Netherlands found that those who had suffered 'moderate' child abuse were eleven times more likely, and those who had suffered 'severe child abuse' forty-eight times more likely, to have 'pathology level psychosis' than people who had not been abused as children (Janssen et al., 2004). The relationships remained after controlling for family history of psychosis, demonstrating, again, that you do not need the supposed genetic predisposition for bad things to drive you crazy.

Rates of childhood neglect for adult inpatients range from $22 \%$ to $62 \%$ (Read, Goodman, Morrison, Ross, \& Aderhold, 2004). In a community survey, women emotionally abused as children were five times more likely to have had a psychiatric admission (Mullen, Martin, Anderson, Romans, \& Herbison, 1996). In a study of adult outpatient 'schizophrenics', 35\% had suffered emotional abuse as children, $42 \%$ physical neglect, and 73\% emotional neglect (Holowka, King, Saheb, Pukall, \& Brunet, 2003). A recent study of first episode schizophrenia-spectrum inpatients (mostly males), which found CSA and CPA rates of 39\% and 78\% respectively, also found the following: emotional abuse, $94 \%$; emotional neglect, 89\%; and physical neglect, 89\% (Compton, Furman, \& Kaslow, 2004).

In a thirty-year study of over 500 child guidance clinic attenders, 35\% of those who later became 'schizophrenic' had been removed from home because of neglect; a rate double that of any other diagnosis (Robins, 1966). Among over 1,000 people, those whose mother-child interactions at age three had been characterized by 'harshness towards the child; no effort to help the child' were, at age twenty-six, more likely than others to have 'schizophreniform disorder', but not mania, anxiety, or depression (Cannon et al., 2002). Adults diagnosed 'schizophrenic' are significantly more likely than the general population to have run away from home as children (Malmberg, Lewis, David, \& Allebeck, 1998; Bebbington et al., 2004), to have attended child guidance centres (Ambelas, 1992), to have been placed in children's homes (Cannon et al., 2001), to have been bullied, and witnessed violence at home (Bebbington et al., 2004).

Emotional abuse has received less attention than physical and sexual abuse. However, it can be argued that the research on 'Expressed Emotion' (EE), a British euphemism for parental hostility, criticism, and emotional intrusiveness has, while avoiding naming these behaviours as abusive (so as not to be 'family blaming'), made a contribution. The creators of the Parental Bonding Instrument (PBI), have indeed argued that the core components of EE 'resemble PBIdefined lack of care and over-protection (a parental style labelled "affectionless control")' (Parker, Hayward, \& Johnston, 1989, p. 444).

Researchers working within the bio-genetic paradigm have focused on the effects of EE on relapse rates rather than investigating its causal role.

John Read and Andrew Gumley 
Nevertheless, a USA study followed adolescents for fifteen years and found that $36 \%$ of those whose parents had both scored high on EE were now diagnosed with 'schizophrenia', compared to $0 \%$ if only one, or neither, parent was high EE (Goldstein, 1987). This might suggest that having one parent to whom one is reasonably securely attached might mitigate the effects of the other parent being hostile, critical, and intrusive.

Even in studies of 'high risk' samples, designed to investigate the genetic predisposition hypothesis, those who end up with 'schizophrenia' are significantly more likely to have had less satisfactory relationships with their parents (using a measure that included parents' own reports) (Burman, Mednick, Machon, Parnas, \& Schulsinger, 1987), more stressful family characteristics (parental attitudes and poverty combined) (Roff \& Knight, 1981), poor family relationships (Tienari, 1991), and, consistent with the EE research above and the PBI research to follow, over-involved or hostile parenting (Marcus, Hans, Nagler, Auerbach, Mirsky, \& Aubrey, 1987).

\section{Parental loss}

A 1966 review reported that eight of thirteen studies had found that 'schizophrenics' have higher rates of parental death in childhood than control groups (Granville-Grossman, 1966). One study that did not find an increase in parental death among people with 'schizophrenia' did find an increase in parental divorce (Brill \& Liston, 1966).

Bleuler (1978) found that $31 \%$ of 932 people diagnosed 'schizophrenic' had lost a parent before age fifteen, a rate significantly greater than the general population. A recent study found that loss of mother during childhood was significantly higher $(55 \%)$ in 'schizophrenics' than for other diagnoses $(23 \%)$ (Friedman et al., 2002). Bereavement in general is related to predisposition to auditory hallucinations in young adults (Morrison \& Petersen, 2003).

A recent British study found that 390 people with a first episode of psychosis were, compared to a control group, 2.4 times more likely to have been separated for at least a year from one of their parents before age sixteen and 3.1 times more likely to have had one of their parents die. They were 12.3 times more likely to have had their mother die. These findings were after controlling for parental history of mental illness, yet again casting doubt on the genetic predisposition requirement for psychosis (Morgan et al., 2007).

An important study, in the context of attachment, found that among people who had lost a parent in childhood those who were later diagnosed with 'schizophrenia' had lost the parent an average of two years earlier (at an average age of about six years old) than a control group (Watt \& Nicholi, 1979). An Israeli study found that death of, or permanent separation from, a parent was only predictive of 'schizophrenia' if occurring in the first eight years of life 
(Agid et al., 1999). Studies of samples with a family history of 'schizophrenia' confirm that the first few years of life are the most important (Parnas, Teasdale, \& Schulsinger, 1985). For example, 'schizophrenia' was predicted by parental separation leading to institutionalization (but not to supportive foster homes) in the first three years (Schiffman et al., 2001), and by separation from parents in the first year (Granville-Grossman, 1966). A recent British study, however, did not replicate these findings (Morgan et al., 2007).

\section{Unwanted pregnancies}

Unwanted pregnancies are predictive of poor social and emotional functioning (Kubicka, Roth, Dytrych, Matejcek, \& David, 2002). In a Finnish study of over 11,000 people, those whose pregnancies had been unwanted by their mothers were 2.5 times more likely to be diagnosed later as having 'schizophrenia' (Myhrman, Rantakallio, Isohanni, Jones, \& Partanen, 1996). A USA study of over 9,000 found the ratio to be 1.75 (Herman et al., 2006). After controlling for mediating variables, the Finnish finding remained statistically significant, the USA finding did not $(p=0.09)$.

\section{The attachment context of early development}

Experiences of loss and trauma are not limited to those individuals who later develop 'schizophrenia'. Two studies have recently explored the relationship between borderline personality disorder (BPD), dissociative disorders, and severe traumas or losses suffered by the mothers of adult patients in the two years before or after the patients' birth (previously shown to increase the risk for infant attachment disorganization). In the first study, a group of sixty-six BPD patients were matched with a control group of 146 psychiatric patients with other disorders (anxiety disorders, affective disorders, and cluster C personality disorders; Liotti, Pasquini, \& The Italian Group for the Study of Dissociation, 2000). In the second study, the same control group was matched with a group of fifty-two patients diagnosed with dissociative disorder (Pasquini, Liotti, Mazzotti, Fassone, Picardi, \& The Italian Group for the Study of Dissociation, 2002). As expected, both the dissociative and the borderline groups showed a significantly higher frequency of major losses and severe traumas in the life of the patients' mothers in the years around the patients' birth. In light of the robust evidence linking unresolved traumas and losses in the mother to attachment disorganization in the offspring (Van Ijzendoorn, Schuengel, \& Bakermans-Kranenburg, 1999) the specific pathogenic effect of the mothers' traumas and losses is likely to have been produced by early infant disorganized attachment. In these two studies, childhood trauma in the patients and losses and/or traumas in the lives of the mothers were found to be independent risk factors for the development of both borderline and dissociative 
disorders. In other words, the risk of developing a dissociative disorder or borderline personality disorder was increased by two (theoretically) independent past conditions: (a) the patient's mother was mourning over a loss (or dealing with a serious trauma) during the patient's infancy and (b) the patient's childhood had been plagued by severe traumatic experiences (losses and/or sexual, emotional, and physical abuse). This combination of risk factors may also be relevant to understanding the developmental pathways of individuals diagnosed with schizophrenia, as a third study suggests.

Persons diagnosed with schizophrenia were not included in the control group in the two studies discussed above because it was felt that schizophrenia, unlike the anxiety and affective disorders included in the control group, might share certain characteristics of presentation seen in borderline and dissociative disorders (e.g., fragmentation of mental states; for review see Moskowitz, Read, Farrelly, Rudegeair, \& Williams, in press) The third study, (Miti \& Chiaia, 2003) however, investigated forty-one patients with dissociative disorders or borderline personality disorder, who were compared to sixty-two patients primarily diagnosed as schizophrenic. No differences were found between those diagnosed with dissociative disorders or borderline personality disorder and schizophrenia with regard to the amount of losses and traumas experienced by the mothers, which was high in all three groups. This finding is consistent with clinical observations reported by Walsh (1978) that parents of young patients diagnosed with schizophrenia narrated losses they suffered just before or after the patient's birth much more often than parents of young patients with different diagnoses. It is, therefore, not unreasonable to conclude that early parental loss and trauma are relevant in the early infant development of those who later develop the symptoms of 'schizophrenia' and that the mechanism may be via early disorganized infant attachment. This data is also consistent with the results of one of the first studies using the Adult Attachment Interview with patients suffering from bipolar disorder, schizoaffective disorder, and schizophrenia, in which a high proportion of all patients' interviews were coded ' $U$ ' (unresolved with respect to loss or trauma), which would normally be seen as suggesting disorganization of early attachments (Dozier \& Lee, 1995; Dozier \& Tyrrell, 1997). Furthermore, and consistent with the findings of Miti and Chiaia (2003) and the observations of Walsh (1978), Favaretto, Torresani, and Zimmerman (2001) found that the parents of adults with psychosis reported that the parenting they had received was less caring compared to non-clinical controls.

\section{Parental Bonding Instrument and psychosis}

We have seen that a range of psychosocial factors are predictive of 'schizophrenia'. Many of these are related to attachment styles. To date, the two bodies

Can Attachment Theory Help Explain the Relationship Between Childhood Adversity and Psychosis? 
of research - social causes of psychosis and attachment research - have co-existed in parallel, with few attempts to integrate the two bodies of knowledge (Gumley \& MacBeth, 2006; Gumley \& Schwannauer, 2006; Berry, Barrowclough, \& Wearden, 2007; Liotti \& Gumley, in press). There have, however, been a number of studies using the previously mentioned Parental Bonding Instrument (PBI).

The PBI retrospectively measures perceptions of parent-child relationships during the first sixteen years of life on two dimensions. The 'caring' scale measures a dimension from empathy, closeness, emotional warmth and affection to neglect, indifference, and emotional coldness. 'Over-protection' ranges from intrusion, excessive contact, control, infantilization, and prevention of independent behaviour to autonomy and allowance of independence (Parker, Tupling, \& Brown, 1979). High scores on both dimensions represents 'affectionate constraint'; low scores on both represents 'neglectful parenting'; high protection and low care is characterized as 'affectionless control', whereas the opposite profile is considered 'optimal parenting' (Winther Helgeland \& Torgersen, 1997).

Almost all studies of PBI scores in relation to psychosis or 'schizophrenia' have found high rates of the 'affectionless control' pattern in which parents are experienced as having exhibited low care and high over-protection. This is consistent across countries: Australia (Parker, Fairley, Greenwood, Jurd, \& Silove, 1982; Hafner \& Miller, 1991), Austria (Willinger, Heiden, Meszaros, Formann, \& Aschauer, 2002), Canada (Byrne, Velamoor, Cernovsky, Cortese, \& Losztyn, 1990), England (Rankin, Bentall, Hill, \& Kinderman, 2005), Italy (Favaretto, Torresani, \& Zimmerman, 2001), Norway (Onstad, Skre, Torgersen, \& Kringlen, 1994; Winther Helgeland \& Torgersen, 1997) and the USA (Warner \& Atkinson, 1988).

Table 1 summarizes these studies in an attempt to determine whether low care or high over-protection, in mothers or in fathers, are particularly characteristic of the families in which people diagnosed with 'schizophrenia' grow up. Parker et al. (1982) found that low care in both fathers and mothers was higher in their 'schizophrenia' group than in their control group. In terms of over-protection, however, this was the case only for fathers. This is consistent with the finding that over-protection by fathers was (after a stepwise discriminant analysis controlling for the contribution of age and gender) the most important variable distinguishing between thirty-one people diagnosed with 'schizophrenia' and their same-sex 'non-schizophrenic' twins (Onstad, Skre, Torgersen, \& Kringlen, 1994). However, Rankin Bentall, Hill, and Kinderman (2005) found that low care and high over-protection were greater, compared to controls, in both mothers and fathers.

One study (Parker, Fairley, Greenwood, Jurd, \& Silove, 1982) used the PBI scores (at retest, i.e., 'when judged clinically as having improved to a significant degree') to allocate each parent to one of the four parenting styles described

John Read and Andrew Gumley 
Table 1. Parental Bonding Instrument scores for 'schizophrenic' vs 'normal' and psychotic vs non-psychotic samples

\begin{tabular}{|c|c|c|c|c|c|c|}
\hline Studies & Country & $n$ & $\begin{array}{c}\text { Paternal } \\
\text { care }\end{array}$ & $\begin{array}{c}\text { Maternal } \\
\text { care }\end{array}$ & $\begin{array}{c}\text { Paternal } \\
\text { over- } \\
\text { protection }\end{array}$ & $\begin{array}{c}\text { Maternal } \\
\text { over- } \\
\text { protection }\end{array}$ \\
\hline \multicolumn{7}{|l|}{ 'Schizophrenia' } \\
\hline Parker et al., $1982^{1,2}$ & Australia & $69 / 72$ & $20.6^{*}$ & $23.9^{*}$ & $14.8^{*}$ & 14.5 \\
\hline Warner \& Atkinson, $1988^{3}$ & USA & 62 & 19.2 & 23.2 & 16.7 & 17.1 \\
\hline Parker et al., $1989^{3}$ & Australia & 57 & 19.4 & 21.9 & 18.1 & 18.1 \\
\hline Byrne et al., $1990^{2}$ & Canada & 14 & $17.8^{*}$ & 22.8 & 11.1 & 16.1 \\
\hline Hafner \& Miller, $1991^{3}$ & Australia & 18 & 20.8 & 23.2 & 15.4 & 19.6 \\
\hline Onstad et al., $1994^{4}$ & Norway & 12 & $17.9^{* *}$ & 20.4 & 16.2 & 15.5 \\
\hline Onstad et al., $1994^{5}$ & & 19 & $17.2^{*}$ & $19.8^{*}$ & $15.5^{* *}$ & 17.4 \\
\hline $\begin{array}{l}\text { Winther Helgeland \& } \\
\text { Torgersen, } 1997^{2}\end{array}$ & Norway & 19 & & $17.1^{* *}$ & & $21.2^{* *}$ \\
\hline Favoretto et al., $2001^{1,3}$ & Italy & 26 & 22.4 & 23.4 & 16.6 & 17.6 \\
\hline Willinger et al., $2002^{6}$ & Austria & 36 & & $21.6^{*}$ & & $19.1^{* *}$ \\
\hline Rankin et al., 2005²,6 & England & 14 & $12.5^{* *}$ & $12.6^{* *}$ & $21.9^{* *}$ & $18.6^{* *}$ \\
\hline Rankin et al., $2005^{2,7}$ & & 9 & $13.1^{* *}$ & $13.0^{* *}$ & 17.3 & 16.9 \\
\hline Weighted average & & & 19.65 & 21.70 & 16.74 & 17.29 \\
\hline \multicolumn{7}{|l|}{ ‘Normal' GP samples } \\
\hline Parker et al., 1979 & USA & 463 & 22.5 & 25.2 & 12.7 & 13.3 \\
\hline Parker, 1983 & Australia & 410 & 23.8 & 26.9 & 12.4 & 13.3 \\
\hline Weighted average & & & 23.11 & 26.00 & 12.56 & 13.30 \\
\hline Difference & & & -3.46 & -4.30 & +4.18 & +3.99 \\
\hline
\end{tabular}

${ }^{*}<0.05 \quad * *<0.01$ compared to control group

${ }^{1}$ midpoint of test and retest scores

2 compared to 'normal' control group

${ }^{3}$ no comparison with a control group

${ }^{4}$ compared to non-schizophrenia MZ twin

5 compared to non-schizophrenia DZ twin

${ }^{6} 75-79 \%$ 'schizophrenia' (100\% psychosis)

7 'schizophrenia in remission'

above. There was a clear pattern of the parents of the 'schizophrenia' group, compared to the 'normal' comparison group, to be categorized as 'affectionless control' (low care, high over-protection) ( $38 \%$ vs $26 \%$ ), with the reverse being the case for 'optimal parenting' (21\% vs $39 \%)$. These findings were not statistically significant for mothers. They were, however, significant for fathers, who were categorized by the 'normal' group as having provided 'optimal parenting' at more than twice the rate as by the 'schizophrenia' group (38\% vs 16\%). Before we conclude too much from just one study about whether mothering or fathering is more important, we should note that another study, which only measured mothers' PBI scores, did find significant differences (Winther Helgeland \& 
Torgersen, 1997). While only 5\% of mothers in the 'schizophrenia' group were characterized as 'optimal parenting', this was the case for $48 \%$ of the 'nonclinical' control group $(p<0.000)$. The figures for 'affectionless control' were 'schizophrenia' 68\%, controls 20\% ( $p<0.005)$.

Table 1 compares the weighted averages of the 'schizophrenia' samples (i.e., giving an appropriately greater weight to the larger samples) with the weighted averages of two samples of 'normal' samples of GP attenders in Australia and the USA (Parker, Tupling, \& Brown, 1979; Parker, 1983). There are notable differences, of between 3.5 and 4.3 scale points, on all four variables, suggesting that both mothers and fathers, and that both low care and high over-protection, are important. The only difference of note here is that in terms of care, the difference between the mothers of the 'schizophrenia' samples and the mothers of the 'normal' samples' (-4.3) is slightly greater than the corresponding difference for fathers (-3.5). This finding is no basis for hypothesizing that the low levels of maternal care experienced by the 'schizophrenia' group are more important than the low levels of paternal care. The mothers (21.70) were still experienced as more caring than the fathers (19.65).

Another way to explore differences between the four variables is to calculate the percentage of significant differences when compared to control groups. This is possible for six samples for fathers and eight samples for mothers (see Table 1). The percentages are: paternal care 100\%; maternal care $75 \%$; paternal over-protection $50 \%$; maternal over-protection $37.5 \%$. Thus $75 \%$ of the comparisons involving fathers were significant, compared to 56\% for mothers. Perhaps the most telling finding is that $86 \%$ (twelve out of fourteen) of the comparisons examining care were significant, compared to only $43 \%$ for over-protection.

The possibility that low care is even more important than high over-protection receives support from a general population study of 4045 people in the Netherlands, which confirmed the relationship between low care (both parents combined) and psychosis, but found no relationship with high over-protection (Janssen et al., 2005). Table 2 presents the data from this important study in a format allowing comparison with the studies in Table 1. In addition, a Scottish study, using a different measure of perceived parental rearing patterns, found that the parents of 'schizophrenia' subjects were not seen as more 'over-protective' or 'rejecting' than the parents of 'normal' subjects, but they were (both mothers and fathers) seen as exhibiting significantly less 'warmth' (McCreadie, Williamson, Athawes, Connolly, \& Tilak-Singh, 1994).

\section{Onset and remission}

PBI may also be related to time of onset and to course as well as to aetiology. In one study, of seventy-two people diagnosed with 'schizophrenia', those who experienced one or both parents as low care and high over-protection had an 
Table 2. Parental Bonding Instrument Scores for 'psychotic' and 'non-psychotic' samples in the Netherlands ${ }^{1}$

\begin{tabular}{lcccc}
\hline & $\begin{array}{c}\text { Paternal } \\
\text { care }(n)\end{array}$ & $\begin{array}{c}\text { Maternal } \\
\text { care (n) }\end{array}$ & $\begin{array}{c}\text { Paternal } \\
\text { over-protection (n) }\end{array}$ & $\begin{array}{c}\text { Maternal } \\
\text { over-protection (n) }\end{array}$ \\
\hline Psychosis & $16.77(64)$ & $20.20(93)$ & $17.51(59)$ & $19.36(88)$ \\
Non-psychotic & $27.61(5148)$ & $30.11(6623)$ & $10.71(5054)$ & $11.58(6573)$ \\
Difference & -10.84 & -9.91 & +6.80 & +7.78 \\
\hline
\end{tabular}

${ }^{1}$ Data from Janssen et al., 2005, kindly provided by the authors on request.

earlier age of first hospitalization and were more likely to be readmitted (Parker, Fairley, Greenwood, Jurd, \& Silove, 1982). Other studies have not found any relationship between perceived parental rearing styles and age of onset (Warner \& Atkinson, 1988; McCreadie, Williamson, Athawes, Connolly, \& Tilak-Singh, 1994). However, it has been found that patients who scored their parents positively on the PBI 'tended to experience a milder course of illness if they were in frequent contact with them, and a more severe course if they were not' (Warner \& Atkinson, 1988, p. 344). The opposite was true for those who perceived their parents negatively (Warner \& Atkinson, 1988). This is consistent with EE research showing that the more time spent with hostile or over-involved parents, the greater the relapse rate (Vaughn \& Leff, 1976).

\section{Specificity}

While the research summarized above clearly demonstrates that affectionless control (low care, high over-protection) is related to psychosis and 'schizophrenia', there is little evidence that the relationship is any stronger or weaker than for other diagnostic groupings. A review of twenty-three studies concluded that affectionless control was the prevalent parental style for six of the eight diagnoses studied, including schizophrenia, but not for bipolar disorder or avoidant personality disorder (Favaretto \& Torresani, 1997). The review also found that the PBI discriminated between normal subjects and schizophrenia and that this was also the case for bipolar disorder, borderline personality disorder, anxiety disorders, and drug addiction. The PBI was not, however, found to discriminate between normal samples and depression, panic attacks, or avoidant personality disorder. Two studies have directly compared PBI scores for 'schizophrenia' and another diagnosis. Both have compared with borderline personality disorder, another diagnosis with extremely high rates of child abuse and neglect. Indeed, the first study found that the 'borderline' group had significantly more CSA and CPA, and also had more paternal overprotection and less maternal care than the 'schizophrenia' group (Byrne, Velamoor, Cernovsky, Cortese, \& Losztyn, 1990). However, the second study, 
which investigated only mothers' PBI scores, found that while both diagnostic groups produced significantly higher over-protection and lower care scores than the 'non-clinical controls', they did not differ from one another on either of the two PBI scores (Winther Helgeland \& Torgensen, 1997).

There has been little research into the relationship between PBI scores and specific psychotic symptoms. The Scottish study that used an alternate measure of parenting styles (McCreadie, Williamson, Athawes, Connolly, \& Tilak-Singh, 1994) found that 'rejection' is correlated with positive symptoms for both mothers and fathers but is also correlated with negative symptoms but for mothers only and not so strongly. 'Over-protection' is correlated with positive symptoms, but for fathers only, and is not correlated with negative symptoms. Lack of warmth is correlated with negative symptoms only (for mothers and fathers).

An additional type of specificity, the gender of the person diagnosed with 'schizophrenia', has also not received much attention. The issues of whether boys and girls might be differentially affected by lack of care or by high overprotection, and whether same-sex parenting is more or less important than cross-sex parenting warrant investigation. Again the Scottish study points the way forward. Both mothers and fathers in the 'schizophrenia' group were more rejecting of daughters than sons, and in addition mothers (but not fathers) showed less warmth to daughters than to sons. However, when analysing the relationships between the parenting styles of mothers and fathers to positive and negative symptoms, and to 'general psychopathology' a strong, and potentially very important, pattern emerged. Of the eighteen correlations involving the sons (the three symptom measures $\times$ the two parents $\times$ the three parenting variables), seven were statistically significant. This was the case for only one of the correlations involving daughters. For example, rejection by mother and by father were both correlated with positive symptoms for sons but not for daughters. This raises the possibility, worthy of further investigation, that the other findings of a relationship between parenting styles and psychosis are predominantly, or only, for sons. This in turn raises the issue of possible gender differences in resilience and sensitivity in relation to neglect or punitive over-control. Different pathways from child abuse to psychosis for boys and girls have been discussed elsewhere and, given the consistently found differences between the genders in symptoms and age of onset, this avenue of research is in need of greater attention (Read, 2004b).

\section{Intergenerational patterns}

Another area that has received insufficient attention is the intergenerational nature of inadequate parenting and insecure attachment. This would seem an important avenue if we are to avoid passing either moral or genetic/psychiatric judgement on parents (Read, Mosher, \& Seymour, 2004) and, instead, strive to 
understand the origins of poor parenting so that prevention and support programmes can be put in place. One exception is an Italian study, which asked twenty-three parents to complete the PBI in relation to their own parents. Compared to non-clinical samples, they had 'similar (moderate) parental control but had received considerably less care, a pattern that is characteristic for absent or weak parental bonding' (Favaretto, Torresani, \& Zimmerman, 2001, p. 127).

\section{Distorted memory: the negative bias hypothesis}

It is possible that, rather than poor parenting being a causal factor for psychosis, an alternative explanation of all these studies is that psychosis negatively biases memory, or report, of childhood events. This is a frequent, but false, critique of the studies showing that child abuse is a causal factor for psychosis (Read, van Os, Morrison, \& Ross, 2005; Read, 2006; Read, Hammersley, \& Rudegeair, 2007). Even if people do express more negative perceptions of their parents while psychotic, it would be wrong to automatically conclude that this represents a negative bias. It is possible that for some people it is only in a relatively disinhibited state such as psychosis that abuse histories and negative feelings about one's parents can be expressed, and that when the psychosis subsides these thoughts and feelings are either unconsciously suppressed or consciously kept to oneself.

A British study explicitly addressed the negative bias critique in relation to PBI, with an ingenious design. The study compared the PBI scores of fourteen 'currently ill paranoid patients' (eleven 'schizophrenia', three delusional disorder), nine 'remitted paranoid patients' (all 'schizophrenia') and fifteen 'health controls'. There were no significant differences between the currently ill and the remitted groups on either the care or the over-protection scores, for mothers or fathers (Rankin, Bentall, Hill, \& Kinderman, 2005). In addition, an Australian study, designed to investigate test-retest reliability of the PBI, provides further evidence refuting the negative bias hypothesis. The PBI was first administered shortly after admission, when sixty-nine of the seventy-one $(97 \%)$ in the 'schizophrenia' sample were 'extremely or moderately distressed', and then again three to four weeks later, when only $41 \%$ were distressed. The PBI scores were 'strikingly similar for the two assessment periods' (Parker, Fairley, Greenwood, Jurd, \& Silove, 1982, p. 576). Furthermore, most of the studies explicitly excluded people who were psychotic at the time of the study. For instance, one of the Italian studies notes that 'none were acutely psychotic at the test or retest' (Favoretto, Torresani, \& Zimmerman, 2001).

\section{Genetically determined 'pre-morbid temperament'?}

Another interpretation of the studies reviewed above is that even if people diagnosed 'schizophrenic' do have harsher family environments, this is a 
consequence rather than a cause of their 'schizophrenia'. Proponents of a simplistic bio-genetic paradigm have often argued, as in the field of child abuse, that any findings demonstrating harsher treatment should be interpreted in terms of parents' reactions to 'pre-morbid' abnormalities in the behaviour of the 'pre-schizophrenic' child, i.e. abnormalities occurring before the development of the disease. For example, Onstad, Skre, Torgersen, and Kringlen (1994) offered several interpretations for their finding that 'schizophrenic' twins report more over-protection and less care than their non-schizophrenic twin. They clearly preferred this one: 'Premorbid abnormalities in the twin with a disposition for schizophrenia may have caused the parents to raise the twin differently' (ibid., p. 69). The faulty logic originates in the incorrect assumption, common throughout the stress-disposition approach of the bio-psychosocial model that the disposition cannot itself be caused by early, abusive, punitive, or neglectful experiences and must be bio-genetic in origin (Read, Perry, Moskowitz, \& Connolly, 2001). Ironically, the study by Onstad, Skre, Torgersen, and Kringlen (1984) provided evidence refuting the argument that harsh treatment of children who later develop 'schizophrenia' is a reaction to pre-existing abnormalities, the origins of which have nothing to do with the environment in which they are raised. They found that for both monozygotic (genetically identical) and dizygotic twins, the twin later diagnosed with 'schizophrenia' reported greater over-protection and less care than the other twin. As the authors point out 'MZ twins are genetically identical and any differences between such twins are due to non-genetic causes' (ibid., p. 67). The Scottish study, moreover, found no significant relationship between 'premorbid personality and social adjustment' (as assessed by the patients' mothers), and parental rearing styles (McCreadie, Williamson, Athawes, Connolly, \& Tilak-Singh, 1994). Also, when we consider the relationship between early trauma and attachment disorganization, meta-analytic evidence shows that disorganized infant attachment does not arise through temperamental (van Ijzendoorn, Schuengel, \& Bakermans-Kranenburg, 1999) or genetic variables (Bokhorst, Bakermans-Kranenburg, Fearon, van Ijzendoorn, Fonagy, \& Schuengel, 2003; Bakermans-Kranenburg \& van Ijzendoorn, 2004).

\section{Why utilise attachment theory to understand psychosis?}

Attachment research (Ainsworth, Blehar, Waters, \& Wall, 1978) demonstrates that by twelve months infants develop different organized patterns of attachment behaviour towards their care-givers, which are consistent with the response they received to their requests for comfort, soothing, and protection. Three main patterns of early organized attachment have emerged: secure, avoidant, and resistant (or ambivalent). However, a minority (around 15\%; van Ijzendoorn,

John Read and Andrew Gumley 
Schuengel, \& Bakermans-Kranenburg, 1999) fail to develop a recognizable, organized (and coherent) attachment pattern. In these cases, the infants' attachments are said to be disorganized (Main, 1991). Secure attachment in the infant is predicted by autonomous states of mind in the caregiver. Ambivalent (resistant) infant attachment is paralleled by the care-giver's preoccupied/enmeshed states of mind. Avoidant infant attachment is associated with an adult stance that is avoidant/dismissing of attachment (Main, 1995; Hesse, 1999).

Disorganization of infant attachment behaviour is statistically linked to unresolved traumas or losses in the care-giver (Main \& Hesse, 1990; van Ijzendoorn, Schuengel, \& Bakermans-Kranenburg, 1999), or to a care-giver's state of mind characterized by non-integrated hostile and helpless representations of self and the attachment figures (Lyons-Ruth, Yellin, Melnick, \& Atwood, 2003). The care-givers' attitudes that mediate between their unresolved/disaggregated states of mind and disorganization of infant attachment behaviour have been hypothesized to be frightening to the infant, either because these attitudes involve abrupt emotional and physical aggression, or because they express fear, helplessness, and dissociative absorption in painful memories (Main \& Hesse, 1990). Empirical evidence that not only aggressive attitudes, but also frightened and dissociative behaviour of the care-giver towards the infant can cause disorganization in the infant's attachment behaviour has been collected by Schuengel, Bakermans-Kranenburg, van Ijzendoorn, and Blom (1999). More recently, Espinosa, Beckwith, Howard, Tyler, and Swanson, (2001) have shown that maternal paranoia is linked to (a) lower ratings of maternal sensitivity during care-giving and (b) disorganized attachment behaviour in their infants. Finally, as stated above, recent meta-analytic evidence shows that disorganized infant attachment does not arise from temperamental (van Ijzendoorn, Schuengel, \& Bakermans-Kranenburg, 1999) or genetic variables (Bokhorst, BakermansKranenburg, Fearon, van Ijzendoorn, Fonagy, \& Schuengel, 2003; BakermansKranenburg \& van Ijzendoorn, 2004).

Therefore, we can understand attachment disorganization as the outcome of intersubjective experiences linked to deficits in the regulation of emotion within the infant-parent dyad, as well as to overtly traumatic experiences (Hesse, Main, Abrams \& Rifkin, 2003; DeOliveira, Neufeld-Bailey, Moran, \& Pederson, 2004). In other words, at least some instances of attachment disorganization are the outcome of subtle relational trauma (Schore, 2003), not of other adverse influences such as evident abuse or primary neurobiological anomalies. Even when early attachment disorganization is not causally linked to maltreatment suffered at the hand of an attachment figure, it yields a vulnerability to respond to later traumas with fragmentation of self experience (Liotti, 1992; Ogawa, Sroufe, Weinfield, Carlson, \& Egeland, 1997), and is therefore of great relevance for the understanding of trauma-related disorders (Liotti, 2004). 
There is some evidence that attachment representations tend to be stable throughout the life span. The child who has been securely attached is likely to become an adult with an autonomous state of mind, while children who have been ambivalent, avoidant, and disorganized in their early attachment are likely to develop preoccupied, dismissing, and unresolved or hostile/helpless states of mind (Benoit \& Parker, 1994; Waters, Merrick, Treboux, Crowell, \& Albersheim, 2000; Lyons-Ruth, Yellin, Mellin, \& Atwood, 2003).

When the Adult Attachment Interview (AAI) is given to samples of adult psychiatric patients with different diagnoses, unresolved and non-integrated (hostile/helpless) are by far the more frequently assessed states of mind, suggesting that early attachment disorganization is a particularly frequent antecedent of adult psychopathology (Dozier, Stovall, \& Albus, 1999; Levy, 2005). The relevance of disorganized attachment for the understanding of developmental pathways leading to schizophrenia has been tentatively suggested by AAI studies that investigated the attachment style in samples of patients suffering from psychotic disorders (Dozier \& Lee, 1995; Dozier \& Tyrrell, 1997). As expected, a substantial proportion of these patients' interviews were coded ' $U$ ' (unresolved with respect to loss or trauma), suggesting disorganization of early attachments. However, Dozier, Stovall, and Albus (1999), commenting on these results, stated 'that these attachment states of mind have little to tell us about the psychological factors predisposing individuals to be diagnosed with schizophrenia' (p. 510). The justification for this statement was the fact that disorganized status on the AAI is based on coded narratives where there are lapses of reasoning and discourse. Persons with psychotic experiences may appear 'unresolved' not because of traumas, losses, and a history of early attachment disorganization, but because of other factors responsible for their thought disorder. However, it is also possible that early adverse attachment experiences contribute to the development of core predictors associated with the development of psychosis. For instance, the genesis of psychotic disorders such as 'schizophrenia' may involve a developmental pathway that links together unresolved traumas and/or losses in parents, early attachment disorganization and its sequelae in the development of the patient's personality, later traumatic experiences, mentalization deficits, and unresolved or hostile/helpless states of mind in the AAI.

\section{Research linking insecure attachment to psychosis and 'schizophrenia'}

A small but growing number of studies have explicitly investigated the relationship between self-reported attachment styles and either psychosis or 'schizophrenia'. There are major conceptual problems in the reliance on self-reported attachment data due to the insecure attachment strategies' propensity to limit self

John Read and Andrew Gumley 
awareness of one's own sense of insecurity (for example in dismissing/avoidant attachment disorganization). In addition, there are also major problems in inferring early developmental attachment (in)security via self-reported attachment style questionnaires. However, self-report studies do provide a basis to understand and characterize the extent to which individuals experience a sense of insecurity and anxiety in the context of close peer or intimate relationships.

By far the largest study was a nationwide USA survey of over 8,000 people between the ages of fifteen and fifty-four, using the three-style attachment model: secure, avoidant, anxious (Mickelson, Kessler, \& Shaver, 1997). The negative relationship between 'schizophrenia' and secure attachment did not reach significance, and was the only one of sixteen diagnostic groupings not to do so. 'Schizophrenia' was, however, positively related to both avoidant $(p<0.001)$ and anxious $(p<0.01)$, as were almost all the other diagnoses. A recent Israeli study, also using the three-style model, found that only five out of thirty (17\%) men diagnosed 'schizophrenic' self-reported a secure attachment style, compared to twenty-two of thirty (73\%) male non-patient controls (Ponizovsky, Nechamkin, \& Rosca, 2007). Another USA community self-report survey (of nearly 2,000 adolescents) found that insecurely attached adolescents scored significantly higher on 'psychoticism' $(p<0.001)$ than securely attached adolescents (Cooper, Shaver, \& Collins, 1998). The same was true of the seven other diagnostic groupings studied.

Dozier, Stevenson, Lee, and Velligan (1992) found that persons with schizophrenia $(n=21)$ relied on more repressing attachment styles than those with affective disorder $(n=19)$. Repressing (avoidant) strategies were associated with lower self-reported psychiatric symptoms compared to individuals who used preoccupied strategies. Dozier and Lee (1995) investigated attachment organization in seventy-six adults with serious mental health problems, of whom twenty-three had a diagnosis of schizophrenia and twenty-seven had bipolar disorder. Participants who relied on avoidant or deactivating attachment strategies reported fewer symptoms and lower affect, whereas those with hyper-activating or preoccupied strategies reported greater affect and symptoms. In a later study (Dozier \& Tyrrell, 1997), attachment organization was investigated in bipolar disorder $(n=7)$, schizoaffective disorder $(n=8)$, and schizophrenia $(n=27)$. Using the three-way classification of attachment organization (autonomous, preoccupied, and dismissing) most of these participants were classified as dismissing of attachment. In terms of the four-way classification (which includes disorganized attachment) almost 50\% of those diagnosed with schizophrenia were classified as disorganized (see Table 3). These findings are clinically important. Deactivating attachment strategies were associated with greater rejection of treatment and less disclosure of symptoms, despite clinician's ratings of symptoms as more severe compared to those utilizing hyper-activating strategies.

Can Attachment Theory Help Explain the Relationship Between Childhood Adversity and Psychosis? 
Table 3. Adult Attachment Interview classifications and diagnosis (from Gumley \& Schwannauer, 2006)

\begin{tabular}{|c|c|c|c|c|c|c|c|}
\hline \multirow[t]{2}{*}{ Diagnosis } & \multicolumn{3}{|c|}{ Three way classification } & \multicolumn{4}{|c|}{ Four way classification } \\
\hline & Secure & $\begin{array}{c}\text { Pre- } \\
\text { occupied }\end{array}$ & Avoidant & Secure & $\begin{array}{c}\text { Pre- } \\
\text { occupied }\end{array}$ & Avoidant & Disorganized \\
\hline Bipolar disorder & 0 & 0 & 7 & 0 & 0 & 3 & 4 \\
\hline Schizoaffective & 1 & 1 & 6 & 1 & 0 & 5 & 2 \\
\hline Schizophrenia & 3 & 0 & 24 & 1 & 0 & 16 & 12 \\
\hline
\end{tabular}

Ponizovsky, Nechamkin, and Rosca, (2007) found that $57 \%$ of men diagnosed 'schizophrenic' self-reported avoidant attachment styles, compared to $17 \%$ of non-patient controls. The figures for anxious/ambivalent were 'schizophrenia' $27 \%$, controls $10 \%$. Thus, consistent with Dozier's findings, the 'schizophrenia' group were slightly more than three times more likely than controls to be avoidant and slightly less than three times more likely to be anxious/avoidant.

\section{Research linking attachment styles to specific symptoms of psychosis}

In keeping with the increasing trend to research specific symptoms rather than the heterogeneous, disjunctive construct 'schizophrenia' (Bentall, 2003), studies that investigate the relationships between attachment and, for instance, negative and positive symptoms, or hallucinations or delusions, might be more informative than studies showing that attachment is just as related to 'schizophrenia' as it is to almost every other diagnostic category.

Three studies of non-clinical psychotic phenomena have found that schizotypal characteristics (positive and negative) are related to insecure attachment (Wilson \& Costanzo, 1996; Berry, Wearden, Barrowclough, \& Liversidge, 2006). Macbeth, Schwannauer, and Gumley (in press) using a covariance modelling approach, found that the combination of self-reported attachment anxiety and avoidance and the use of interpersonal distancing/affiliating strategies were associated with paranoia and hallucinations. It was noteworthy that there were important differences in the nature of predictions between paranoia and hallucinations. Paranoia seemed to be predicted by an 'organized' model consisting of attachment anxiety, avoidance, and interpersonal distancing strategies; whereas the hallucinations model was more complex and portrayed a more conflicted picture coupling a combination of attachment anxiety and interpersonal affiliating strategies with attachment avoidance and interpersonal distancing strategies. The authors speculated that this latter model gave a picture for hallucinations that represented apparently contradictory and competing interpersonal strategies, suggesting a disorganization in affect and 
interpersonal regulation. Such a picture might provide an analogue for disorganized attachment models.

The Israeli study mentioned above found that, while positive symptoms were related to both avoidant and anxious/ambivalent styles, negative symptoms were related only to the avoidant style (Ponizovsky, Nechamkin, \& Rosca, 2007). This pattern had also been found in a non-clinical sample, with avoidant related to negative schizotypal traits, including loss of pleasure and social withdrawal, but both anxious and avoidant related to positive symptoms, including bizarre beliefs and anomalous experiences (Wilson \& Costanzo, 1996). This pattern of findings was also replicated by the more recent of the two studies of non-clinical psychotic phenomena (Berry, Wearden, Barrowclough, \& Liversidge, 2006). Both insecure attachment styles were significantly related to paranoia and hallucinations (positive) and social anhedonia (negative). However, paranoia and hallucinations were significantly more related to anxious attachment than to avoidant, and social anhedonia was significantly more related to avoidant than anxious.

Dozier and Lee (1995) found that all four types of positive symptoms studied (delusions, auditory hallucinations, suspiciousness, and loose thinking) were significantly correlated with deactivating by one group of interviewers but not the other. However, all eight possible correlations were in the same direction, i.e., correlated with deactivating rather than activating styles. Both groups produced a positive correlation between deactivating and 'global psychosis'. This is evidence of a relationship between deactivating and positive symptoms only. Negative symptoms were not included.

Finally, a very recent British study using a student sample has just found that insecure attachment is specifically associated with paranoia but not hallucinations (Pickering, Simpson \& Bentall, in press).

\section{Cognitive, affective and interpersonal processes involved in the relationships between childhood adversity, insecure attachment and psychosis}

Now that psychosis has been demonstrated to be associated with childhood trauma, loss, and neglect, to sub-optimal parenting styles and to insecure attachment, some researchers are developing theories about the processes involved (Gumley \& MacBeth, 2006; Gumley \& Schwannauer, 2006; Berry, Barrowclough, \& Wearden, 2007; Liotti \& Gumley, in press). The question is: how can attachment theory help to explain the relationship between childhood adversity and psychosis? At this stage there are clearly more questions than answers, but the fact that these questions are being asked, and addressed by researchers, is a major step out of the darkness of the preceding several decades when such questions were virtually taboo (Read, Mosher, \& Bentall, 2004).

Can Attachment Theory Help Explain the Relationship Between Childhood Adversity and Psychosis? 
Current theorizing, and the questions generated, focus on three broad areas: cognitive processes, including both negative thought processes (about self and others) and mentalization, affect dysregulation, and damaged or non-existent relationships. What is already clear is that these three domains cannot be separated. Gumley and Schwannauer (2006, p. 46) suggest:

It may be that early adverse experiences contribute to the development of core predictors associated with the development of psychosis and the emergence of a negative trajectory of psychosis. This is characterised by problematic emotional and interpersonal adaptation, heightened sensitivity to interpersonal stress (e.g. criticism and emotional over-involvement), poor pro-social coping and helpseeking, social withdrawal and avoidant and/or conflicted coping styles, and impoverished reflective function and affect regulation.

Berry, Barrowclough, and Wearden (2007) argue, 'Attachment theory has the potential to provide a useful theoretical framework for conceptualising the influence of social cognition, interpersonal and affective factors on the development and course of psychosis, thus integrating and enhancing current psychological models' (p. 472).

In other words, there have been significant developments of psychological models of psychosis in all of the three areas, and attachment styles, which 'reflect individual differences in beliefs about self and others, interpersonal functioning and affect regulation' (ibid., p. 458), might seem the ideal approach for understanding how these three domains interact, following childhood adversity, to produce psychosis.

\section{Cognition}

Over the past fifteen years or so, cognitive theorists, primarily in the UK, have been significantly enhancing our understanding of psychosis by studying the thought processes and cognitive styles underlying hallucinations and delusions (Garety, Kuipers, Fowler, Freeman, \& Bebbington, 2001; Bentall, 2003). These include making external, personal attributions for negative events, jumping to conclusions on the basis of limited data, and misinterpreting internal thoughts or memories as external events ('source monitoring'). At the heart of most cognitive theory is the idea that we develop 'schema' about the world, including ourselves and other people. These have been deployed in attempts to understand the link between childhood abuse and psychosis (Larkin \& Morrison, 2006). The schema developed by abused children influence how anomalous experiences are interpreted later in life and the distress involved with the faulty interpretations based on negative schema contribute to determining who becomes psychotic (Fowler et al., 2006). 
The 'internal working models' of relationships revealed by attachment theory are quite similar to the core schema of the cognitive theorists. Berry, Barrowclough, and Wearden (2007) point out, however, that 'working models differ from traditional conceptualisations of schemata in that they reflect more motivated and affectively charged constructs, representing emotional states associated with interpersonal relationships as well as beliefs' (p. 465). So attachment theory has overlaps with cognitive theory, but its potential to integrate the various psychological approaches to making sense of madness is that it specifically focuses on cognitions about the other two domains: affect and relationships. In so doing, it is particularly well placed to help us understand the processes by which childhood abuse or neglect, interpersonal events with potentially dire affective consequences, can lead to psychosis later in life.

\section{Mentalization}

Liotti and Gumley (in press) have recently argued that metacognition could also be of importance in determining whether early disorganized attachment and later traumas lead to schizophrenia, or to borderline or dissociative disorders. Fonagy and his collaborators argue that different, though related, concepts such as 'metacognition' and 'Theory of Mind' may be ultimately reduced to the capacity to reflect on experiences, and have called this overall capacity 'mentalization' or 'reflective functioning'. Mentalization refers to 'mind-mindedness', and the reflective function describes the processes by which mind-mindedness is acquired. Mentalization may be defined as the process by which we come to understand that having a mind mediates our experience of the world via the representation of psychological states. It refers to an intentional stance characterized by the interpersonal awareness that experiences give rise to certain beliefs and emotions, and that particular beliefs, desires, and intentions tend to result in corresponding types of behaviour. This intentional stance is essential in the creation of a continuity of self-experience that is the underpinning of a coherent self-structure.

Since Frith (1992), the association between mentalization (which he called 'Theory of Mind') and the core symptoms of schizophrenia have been an important area of research. Robust evidence has now emerged to show that mentalization is impaired among persons with a diagnosis of schizophrenia compared to non-patient controls (Sprong, Schothorst, Vos, Hox, \& van Engeland, 2007). Sprong and colleagues found that mentalization was impaired among patients in remission, which indicates that deficits in this overall capacity are not merely a consequence of acute symptoms and may reflect a more stable vulnerability factor salient to the development of schizophrenia. Indeed, mentalization deficits have been found in persons at high genetic risk of developing schizophrenia (Schiffman, Lam, Jiwatram, Ekstrom, Sorensen, \& Mednick, 
2004; Marjoram, Miller, McIntosh, Cunningham Owens, Johnstone, \& Lawrie, 2006) and among those with schizotypy (Pickup, 2006). Another finding of Sprong and colleagues' (2007) meta-analysis deserves consideration: schizophrenic patients whose states of mind are disorganized by acute psychotic experiences performed more poorly in mentalization tasks than patients with more organized states of mind (paranoid patients and patients in remission). This finding is consistent with the proposal that acute and disorganizing psychotic experiences are linked to the collapse of self-reflective capacity, which in turn may be the consequence of the collapse in the controlling strategies (or of the disinhibition of attachment needs) that kept at bay the dissociating influence of a disorganized Internal Working Model of early attachment.

\section{Affect}

It has long been accepted that heightened sensitivity to stress and dysregulated affect are common features of psychosis. For decades this tendency to emotionally over-react to stress was seen as an inherited 'vulnerability' or 'predisposition' in the stress-vulnerability model of 'schizophrenia'. In this 'bio-psychosocial' model, the role of social events such as child abuse, etc., was relegated to that of merely triggering the underlying, genetically-based hypersensitivity (Bentall, 2003; Read, Mosher \& Bentall, 2004). Attempts to understand the sensitivity, or inability to regulate affective response to stressors, typically focused on the brain, particularly dopamine and the stress regulation systems in the hypothalamic-pituitary-adrenal (HPA) axis. This was not the original intent of those who first proposed the bio-psychosocial model. The inventors of the stress-vulnerabilty model stated that there is such a thing as 'acquired vulnerability' and that this can be 'due to the influence of trauma, specific diseases, perinatal complications, family experiences, adolescent peer interactions, and other life events that either enhance or inhibit the development of subsequent disorder' (Zubin \& Spring, 1977, p. 109). It has since been demonstrated that the brain processes accompanying the oversensitivity and affect dysregulation in people labelled 'schizophrenic' are found in the brains of traumatized young children (Read, Perry, Moskowitz, \& Connolly, 2001). Thus, the sensitivity so often assumed to be genetic in origin in the stress-vulnerability model within the bio-psychosocial paradigm, can actually be caused by the environment. The obvious fact that the brain is designed to respond to the environment is missed by many brain researchers in the field of 'schizophrenia'.

One group of cognitive researchers in the UK who have not only demonstrated the link between trauma and psychosis (Bebbington et al., 2004) but who place a particular emphasis on affect in their theorizing about the aetiology of psychosis, have proposed a role for emotional dysregulation, embedded in a psychological rather than biological framework (Garety, Kuipers, Fowler, 
Freeman, \& Bebbington, 2001; Fowler et al., 2006). Berry, Barrowclough, and Wearden (2007) make the important link between the cognitive and affective domains, with our third domain, relationships, when they point out that

Negative beliefs about the self and others associated with insecure attachment would increase sensitivity to criticism and negative responses from others. Difficulties in regulating affect and subsequent hyperarousal associated with insecure attachment styles would also increase sensitivity to stress in the social environment. (p. 466)

Trauma researchers and clinicians have long understood the importance of understanding post-traumatic symptomatology as dysfunctional but understandable attempts to regulate affect, and have concentrated their treatment on strategies to decondition the emotional responses to triggering stimuli or memories (Briere, 2002). It can be argued that the ultimate coping mechanism for regulating overwhelming affect is dissociation. Many researchers have highlighted the diagnostic and symptomatic overlap of psychosis with both post traumatic stress disorder (PTSD) (Jankowski, Mueser, \& Rosenberg, 2006; Seedat, Stein, Oosthuizen, Emsley, \& Stein, 2003) and dissociative disorders (Ross, 2004). Numerous studies have found high levels of dissociation in samples of psychosis and 'schizophrenia' (Ross, 2004; Kilcommons \& Morrison, 2005; Schafer et al., 2006). Significant correlations between dissociation and both emotional and physical abuse have been found among adults experiencing psychosis (Holowka, King, Saheb, Pukall, \& Brunet, 2003). It has been argued that attachment disorganization is essentially a dissociative process (Liotti, 2006) arising from the irresolvable conflict of being neglected or abused by one's usual source of comfort, characterized as 'fright without solution' (Main \& Hesse, 1990; Cassidy \& Mohr, 2001). Others have argued that psychosis is also an essentially dissociative process (Ross, 2004; Moskowitz, Read, Farrelly, Rudegeair, \& Williams, in press).

Given that the heightened sensitivity to stress, the affect dysregulation, and the various attempts to regulate potentially overwhelming stress all seem to originate in the interpersonal domain, it should not be surprising that the third domain that has to be considered if we are to fully understand the link between childhood adversity and psychosis is the domain of relationships. Again, attachment theory is potentially very valuable in making sense of the 'interpersonal deficits' found so frequently in psychosis and 'schizophrenia'.

\section{Relationships}

It is in the interpersonal domain that the cognitive and affective difficulties originating in childhood experiences and perpetuated by the resultant attachment styles ('internal working models' of self and others) are played out, often

Can Attachment Theory Help Explain the Relationship Between Childhood Adversity and Psychosis? 
with painful and debilitating outcomes. One of the most limiting consequences of our obsession with genes, neurotransmitters, and medical-sounding diagnoses, has been the lack of emphasis on what has happened, and what is happening now, in the interpersonal lives - or lack thereof - of people thought to have this 'illness' called 'schizophrenia'. There have been exceptions, but psychiatrists who have tried to make sense of psychosis by focusing on the interpersonal context have often been ignored (Sullivan, 1962) or vilified (Laing \& Esterson, 1970). Psychologists, meanwhile, tended for decades to limit their interest in this area to teaching social skills, which is very important but hard to do well if the reasons for the interpersonal difficulties are not addressed.

Attachment theory, almost by definition, is the ideal approach to understanding the fear that so often permeates efforts to establish intimate relationships. In 'schizophrenia' these relationship difficulties are often portrayed as 'negative symptoms', such as 'social withdrawal'. They are seen as just another expression of the illness.

Isolation, abnormal ways of communicating, and disturbed peer relationships are all predictors of psychosis (Harvey, 2001; Mason, Startup, Halpin, Schall, Conrad, \& Carr, 2004). Having fewer than two friends, not having a girlfriend, and feeling interpersonally sensitive are all strong predictors of 'schizophrenia' for adolescent heterosexual males (Malmberg, Lewis, David, \& Allebeck, 1998).

It is in late adolescence and early adulthood that psychosis usually begins. Astonishingly little attention has been paid to the interpersonal, developmental tasks of that period of life when trying to understand 'why then?' One exception is a book entitled Why Does Schizophrenia Develop at Late Adolescence? (Harrop \& Trower, 2003). The rather obvious issues of autonomy and separation are finally given the attention they merit. Attachment theory is hugely relevant to these tasks.

Beyond insecure attachment being an impediment to the complex and often painful tasks of adolescence there is another way in which avoidant or anxious attachment styles, developed earlier, may facilitate psychosis. Adolescence is, of course, a time of experimentation, not least in terms of identity. We all develop rather strange ideas at this time of our lives, experimental ideas you might say, about ourselves, others, and the world at large. Those of us who, because of painful experiences early in our lives, are thinking negative and distorted thoughts about ourselves and others are most likely to be missing a vital corrective influence on those thoughts - a peer group. While those with sufficiently secure attachment might be brave enough to ask a trusted friend, 'Do you think those people were making fun of me?', or 'Do you think I'm a bit odd?', those most in need of being told 'Don't be so silly' are living in isolation. The odd thoughts are free to grow, within a lonely and increasingly frightening world, into psychosis.

John Read and Andrew Gumley 


\section{Conclusions}

Attachment theory, with its explicit focus on Internal Working Models that are most important for the regulation of relationships and affect, seems ideal for furthering our understanding of precisely how abuse, neglect, and loss in childhood can lead to psychosis later in life.

Figure 1 attempts to portray diagrammatically, albeit in a rather simplistic fashion, how the various bodies of research literature reviewed above might fit together.

Further research is required to maximize the potential of attachment theory in this area. We are really just at the beginning of using this theory to unravel issues of specificity to psychosis in general and to individual psychotic symptoms like hallucinations, delusions, thought disorder, and the 'negative' symptoms. Researchers may be well advised to pay more attention to gender differences in designing their studies.

We still have much to learn about which types of adversity are, more than others, causal of insecure attachment (which in turn is predictive of psychosis). The authors of the largest attachment study of 'schizophrenia' concluded that 'the strongest connections involved interpersonal traumas such as physical abuse and serious neglect rather than more abstract characteristics of parents, such as judged warmth and consistency' (Mickelson, Kessler, \& Shaver, 1997, p. 1104). One of the many advantages of attachment theory, however, is that it maintains our focus on the ongoing circumstances of childhood as well as the more obvious, discrete abusive events. It seems too early to rule out the

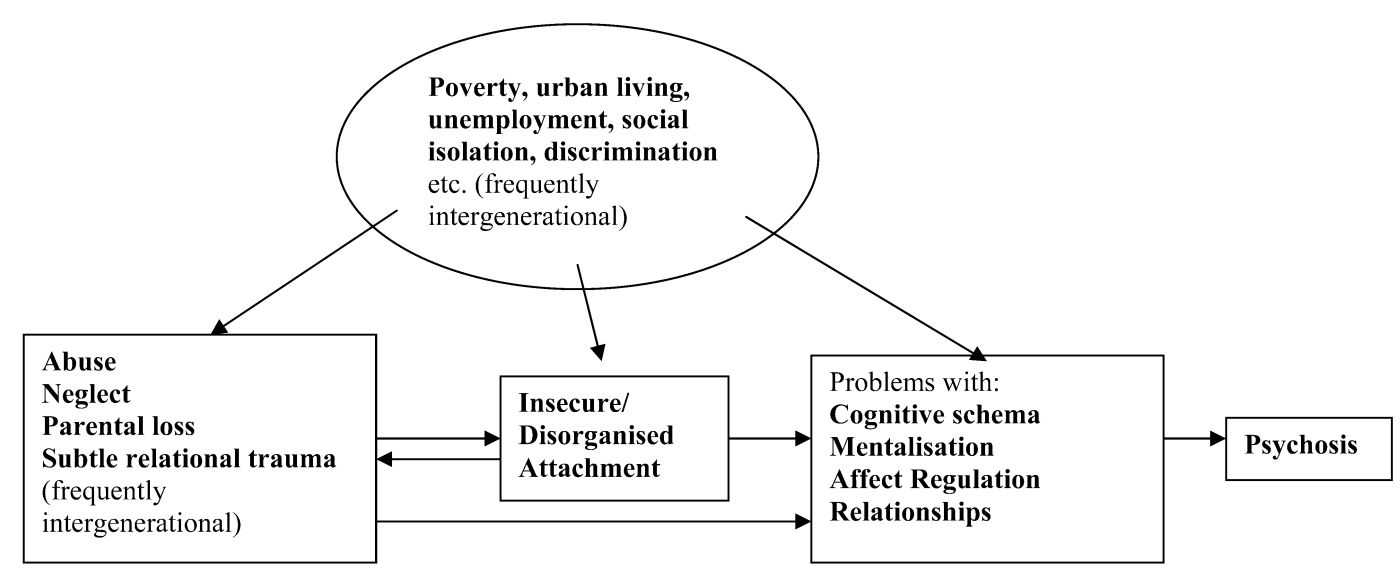

Figure 1. A diagram of the role attachment may play in the relationship between childhood adversity and psychosis.

*The two-directional arrows indicate that insecure/disorganized attachment resulting from childhood adversity can increase probability of further abuse and neglect, e.g., in adolescence.

Can Attachment Theory Help Explain the Relationship Between Childhood Adversity and Psychosis? 
possibility that different types of adversity are differentially predictive of different types of psychotic symptoms, or that these specificities vary by gender.

It seems that Berry and her colleagues are right to assert that investigations of the nature of attachment styles in psychosis and how they relate to the cognitive, interpersonal and affective factors that have been implicated in psychosis will help develop theoretical knowledge in relation to the condition' $(2007$, p. 458).

There have recently been repeated calls, with a slow but growing response, for all mental health staff to include child abuse and neglect in their assessment protocols, with training programmes developed to assist staff in this invaluable endeavour (Read, Hammersley, \& Rudegeair, 2007). It seems that researchers and clinicians addressing psychosis would also be well advised to routinely include a systematic and careful assessment of developmental experiences, attachment states of mind, and Reflective Function (e.g., Gumley, Schwannauer, Birchwood, Davidson, McCabe, \& Blair, 2006).

Given the research reviewed in this paper, knowledge about the most effective approaches to assisting people with attachment disorders (Brisch, 2002) will probably be extremely valuable in assisting people who experience and are recovering from psychotic experiences such as hallucinations and delusions (Gumley \& MacBeth, 2006; Gumley \& Schwannauer, 2006).

Our future research and clinical efforts should not only focus on the damage done by insecure attachment. The positive impact of having at least one adult to whom we are securely attached in childhood, the other side of the coin, deserves equal attention. As noted earlier, the USA study which found that $36 \%$ of adolescents whose mothers and fathers had both scored high in 'Expressed Emotion' were later diagnosed with 'schizophrenia', also found that if one parent scored high but the other low none was later diagnosed with 'schizophrenia' (Goldstein, 1987). An Israeli study (Canetti et al., 2000) that found a relationship between parental loss and 'psychoticism' also found that the relationship was not statistically significant for those children whose remaining parent scored highly on the PBI measure of parental warmth and low on over-protection.

A summary of this paper was presented at the 'Ways towards secure attachment in family and society: International and Interdisciplinary Conference', LudwigMaximilians-Universität, Munich, Germany, December, 2007.

\section{References}

Ainsworth, M., Blehar, M., Waters, E., \& Wall, S. (1978). Patterns of Attachment: A Psychological Study of the Strange Situation. Hillsdale, NJ: Erlbaum.

Agid, O., Shapira, B., Zislin, J., Ritsner, M., Hanin, B., Murad, H., Troudart, T., Bloch, M., Heresco-Levy, U., \& Lerer, B. (1999). Environment and vulnerability to major psychiatric illness: a case control study of early parental loss in major depression, bipolar disorder and schizophrenia. Molecular Psychiatry, 4: 163-172.

John Read and Andrew Gumley 
Ambelas, A. (1992). Preschizophrenics: adding to the evidence, sharpening the focus. British Journal of Psychiatry, 31: 401-44.

Angermeyer, M., \& Dietrich, S. (2006). Public beliefs about and attitudes towards people with mental illness: a review of population studies. Acta Psychiatrica Scandinavica, 113: 163-179.

Bakermans-Kranenburg, M., \& van Ijzendoorn, M. (2004). No association of the dopamine D4 receptor (DRD4) and $-521 \mathrm{C} / \mathrm{T}$ promoter polymorphisms with infant attachment disorganization. Attachment \& Human Development, 6: 211-218.

Bebbington, P., Bhugra, D., Brugha, T., Singleton, N., Farrell, M., Jenkins, R., Lewis, G., \& Meltzer, H. (2004). Psychosis, victimization and childhood disadvantage: evidence from the second British national survey on psychiatric morbidity. British Journal of Psychiatry, 185: 220-226.

Benoit, D., \& Parker, K. (1994). Stability and transmission of attachment across three generations. Child Development, 65: 1444-1456.

Bentall, R. (2003). Madness Explained: Psychosis and Human Nature. London: Penguin.

Bentall, R., Fernyhough, C., Morrison, T., Lewis, S., \& Corcoran, R. (2007). Prospects for a Cognitive Developmental account of psychotic experiences. British Journal of Clinical Psychology, 46: 155-173.

Berry, K., Barrowclough, C., \& Wearden, A. (2007). A review of the role of attachment style in psychosis: unexplored issues and questions for further research. Clinical Psychology Review, 27: 458-475.

Berry, K., Wearden, A., Barrowclough, C., \& Liversidge, T. (2006). Attachment styles, interpersonal relationships and psychotic phenomena in a non-clinical student sample. Personality and Individual Differences, 41: 707-718.

Bhugra, D., Leff, J., Mallett, R., \& Der, G. (1997). Incidence and outcome of schizophrenia in whites, Afro-Caribbeans and Asians in London. Psychological Medicine, 27: 791-798.

Birchwood, M. (2003). Pathways to emotional dysfunction in first-episode psychosis. British Journal of Psychiatry, 182: 373-375.

Bleuler, M. (1978). The Schizophrenic Disorders. S. Clemens (Trans.). New Haven, Connecticut: Yale University Press.

Bokhorst, C., Bakermans-Kranenburg, M., Fearon, P., van Ijzendoorn, M., Fonagy, P., \& Schuengel, C. (2003). The importance of shared environment in mother-infant attachment security: a behavioural-genetic study. Child Development, 74: 1769-1782.

Briere, J. (2002). Treating adult survivors of severe childhood abuse and neglect. In: J. Myers et al. (Eds.), ASPAC Handbook on Child Maltreatment (2nd edn). Newbury Park, CA: Sage.

Brill, N., \& Liston, E. (1966). Parental loss in adults with emotional disorders. Archives of General Psychiatry, 14: 307.

Brisch, K. (2002). Treating Attachment Disorders; From Theory to Therapy. London: Guilford.

Burman, B., Mednick, S., Machon, R., Parnas, J., \& Schulsinger, F. (1987). Children at high risk for schizophrenia: parent and offspring perceptions of family relationships. Journal of Abnormal Psychology, 96: 364-366.

Can Attachment Theory Help Explain the Relationship Between Childhood Adversity and Psychosis? 
Byrne, C., Velamoor, V., Cernovsky, Z., Cortese, L., \& Losztyn, S. (1990). A comparison of borderline and schizophrenic patients for childhood life events and parent-child relationships. Canadian Journal of Psychiatry, 35: 590-595.

Canetti, L., Bachar, E., Bonne, O., Agid, O., Lerer, B., Kaplan De-Nour, A., Shaler, A. Y. (2000). The impact of parental death versus separation from parents on the mental health of Israeli adolescents. Comprehensive Psychiatry, 41: 360-368.

Cannon, M., Caspi, A., Moffitt, T., Harrington, H., Taylor, A., Muray, R., \& Poulton, R. (2002). Evidence for early-childhood, pan-developmental impairment specific to schizophreniform disorder: results from a longitudinal birth cohort. Archives of General Psychiatry, 59: 449-456.

Cannon, M., Walsh, E., Hollis, C., Kargin, M., Taylor, E., Murray, R., \& Jones, P. (2001). Predictors of later schizophrenia and affective psychosis among attendees at a child psychiatry department. British Journal of Psychiatry, 178: 420-426.

Cassidy, J., \& Mohr, J. (2001). Unsolvable fear, trauma and psychopathology: theory, research and clinical considerations related to disorganized attachment across the life cycle. Clinical Psychology: Science and Practice, 8: 275-278.

Compton, M., Furman, A., \& Kaslow, N. (2004). Preliminary evidence of an association between childhood abuse and cannabis dependence among African American firstepisode schizophrenia-spectrum disorder patients. Drug and Alcohol Dependence, 76: 311-316.

Cooper, M., Shaver, P., \& Collins, N. (1998). Attachment styles, emotion regulation, and adjustment in adolescence. Journal of Personality and Social Psychology, 74: 1380-1397.

DeOliveira, C., Neufeld-Bailey, H., Moran, G., \& Pederson, D. (2004). Emotion socialization as a framework for understanding the development of attachment disorganization. Social Development, 13: 437-467.

Dozier, M., \& Lee, S. (1995). Discrepancies between self- and other-report of psychiatric symptomatology: effects of dismissing attachment strategies. Development and Psychopathology, 7: 217-226.

Dozier, M., \& Tyrrell, C. (1997). Attachment and communication among persons with serious psychopathological disorders. In: J. Simpson \& W. Rholes (Eds.), Attachment Theory and Close Relationships. New York: Guilford.

Dozier, M., Stevenson, A., Lee, S., \& Velligan, D. (1992). Attachment organizaton and familial overinvolvement for adults with serious psychopathological disorders. Development and Psychopathology, 3: 475-489.

Dozier, M., Stovall, K .C., \& Albus, K. E. (1999). Attachment and psychopathology in adulthood. In: J. Cassidy \& P. Shaver P. (Eds), Handbook of Attachment (pp. 497-519). New York: Guilford.

Espinosa, M., Beckwith, L., Howard, J., Tyler, R., \& Swanson, K. (2001). Maternal psychopathology and attachment in toddlers of heavy cocaine-using mothers. Infant Mental Health Journal, 22: 316-333.

Favaretto, E., \& Torresani, S. (1997). Il legame genitoriale come fattore predittivo dello sviluppo di disturbi psichiatrici in eta adulta. Epidemiologia e Psichiatria Sociale, 6: $124-138$. 
Favaretto, E., Torresani, S., \& Zimmerman, C. (2001). Further results on the reliability of the parental bonding instrument in an Italian sample of schizophrenic patients and their parents. Journal of Clinical Psychology, 57: 119-139.

Friedman, S., Smith, L., Fogel, D., Paradis, C., Viswanathan, R., Ackerman, R., \& Trappler, B. (2002). The incidence and influence of early traumatic life events in patients with panic disorder: comparison with other psychiatric outpatients. Anxiety Disorders, 16: 259-272.

Frith, C. D. (1992). The Cognitive Neuropsychology of Schizophrenia. Hove, UK: Psychology Press.

Fowler, D., Freeman, D., Steel, C., Hardy, A., Smith, B., Hackman, C., Kuipers, E., Garety, P., \& Bebbington, P. (2006). The catastrophic interaction hypothesis: how do stress, trauma, emotion and information processing abnormalities lead to psychosis? In: W. Larkin \& A. Morrison (Eds.), Trauma and Psychosis (pp. 101-124). London: Routledge.

Garety, P., Kuipers, E., Fowler, D., Freeman, D., \& Bebbington, P. (2001). A cognitive model of the positive symptoms of psychosis. Psychological Medicine, 31: 189-195.

Garfield, S. (1995). Unbearable Affect: A Guide to the Psychotherapy of Psychosis. Oxford: John Wiley \& Sons.

Goldstein, M. (1987). The UCLA High-Risk Project. Schizophrenia Bulletin, 13: 505-514.

Granville-Grossman, K (1966). Early bereavement and schizophrenia. British Journal of Psychiatry, 112: 1027-1039.

Gumley, A., \& MacBeth, A. (2006). A trauma-based model of relapse in psychosis. In: W. Larkin \& A. Morrison (Eds.), Trauma and Psychosis (pp. 283-304). London: Routledge.

Gumley, A., \& Schwannauer, M. (2006). Staying Well After Psychosis: A Cognitive Interpersonal Approach to Recovery and Relapse Prevention. Chichester: Wiley.

Gumley, A., White, C. A., \& Power, K. (1999). An interacting cognitive subsystems model of relapse and the course of psychosis. Clinical Psychology and Psychotherapy, 6: 261-279.

Gumley, A., Schwannauer, M., Birchwood, M., Davidson, K., McCabe, R., \& Blair, A. (2006). The Glasgow Edinburgh First Episode Study. Chief Scientist Office: Scottish Government. Grant Reference Number CZH/4/295.

Hafner, R., \& Miller, R. (1991). Predicting schizophrenia outcome with self-report measures of family interaction. Journal of Clinical Psychology, 47: 33-41.

Hammersley, P., Dias, A., Todd, G., Bowen-Jones, K., Reilly, B., \& Bentall, R. (2003). Childhood traumas and hallucinations in bipolar affective disorder. British Journal of Psychiatry, 182: 543-547.

Harrison, G., Gunnell, D., Glazebrook, C., Page, K., \& Kwiecinski, R. (2001). Association between schizophrenia and social inequality at birth. British Journal of Psychiatry, 179: 346-350.

Harrison, G., Owens, D., Holton, A., Neilson, D., \& Boot, D. (1988). A prospective study of severe mental disorder in Afro-Caribbean patients. Psychological Medicine, 18: 643-657.

Harrop, C., \& Trower, P. (2003). Why Does Schizophrenia Develop at Late Adolescence? A Cognitive-Developmental Approach to Psychosis. London: Wiley.

Can Attachment Theory Help Explain the Relationship Between Childhood Adversity and Psychosis? 
Harvey, P. (2001). Vulnerability to schizophrenia. In: R. Ingram \& J. Price (Eds.), Vulnerability to Psychopathology: Risk Across the Lifespan (pp. 355-365). New York: Guilford.

Herman, D., Brown, A., Opler, M., Desai, M., Malaspina, D., Bresnahan, M., Schaefer, C., \& Susser, E. (2006). Does unwantedness of pregnancy predict schizophrenia in the offspring? Findings from a prospective birth cohort study. Social Psychiatry and Psychiatric Epidemiology, 41: 605-610.

Hesse, E. (1999). The Adult Attachment Interview: Historical and current perspectives. In: J. Cassidy \& P. R. Shaver (Eds.), Handbook of Attachment (pp. 395-433). New York: Guilford.

Hesse, E., Main, M., Abrams, K., \& Rifkin, A. (2003). Unresolved states regarding loss or abuse can have 'second-generation' effects: disorganized, role-inversion and frightening ideation in the offspring of traumatized non-maltreating parents. In: D. Siegel \& M. Solomon (Eds.), Healing Trauma: Attachment, Mind, Body and Brain (pp. 57-106). New York: Norton.

Holowka, D., King, S., Saheb, D., Pukall, M., \& Brunet, A. (2003). Childhood abuse and dissociative symptoms in adult schizophrenia. Schizophrenia Research, 60: 87-90.

Jankowski, M., Mueser, K., \& Rosenberg, S. (2006). Psychosis with comorbid PTSD. In: W. Larkin \& A. Morrison (Eds), Trauma and Psychosis: New Directions for Theory and Therapy (pp. 75-100). London: Routledge.

Janssen, I., Hanssen, M., Bak, M., Bijl, R., De Graaf, R., Vollebergh, W., McKenzie, K., \& Van Os, J. (2003). Discrimination and delusional ideation. British Journal of Psychiatry, 182: 71-76.

Janssen, I., Krabbendam, L., Bak, M., Hanssen, M., Vollebergh, W., de Graff, R., \& van Os, J. (2004). Childhood abuse as a risk factor for psychotic experiences. Acta Psychiatrica Scandinavica, 109: 38-45.

Janssen, I., Krabbendam, L., Hanssen, M., Bak, M., Vollebergh, W., de Graff, R., \& van Os, J. (2005). Are apparent associations between parental representations psychosis risk mediated by early trauma? Acta Psychiatrica Scandinavica, 112: 372-375.

Kilcommons, A., \& Morrison, A. (2005). Relationships between trauma and psychosis: an exploration of cognitive factors. Acta Psychiatrica Scandinavica, 112: 351-359.

King, K., Coker, E., Leavey, G., Hoare, A., \& Johnson-Sabine, E. (1994). Incidence of psychotic illness in London: comparison of ethnic groups. Brtish Medical Journal, 309: 1115-1119.

Kubicka, L., Roth, Z., Dytrych, Z., Matejcek, Z., \& David, H. (2002). The mental health of adults born of unwanted pregnancies, their siblings and matched controls. Journal of Nervous and Mental Disease, 190: 653-662.

Laing, R., \& Esterson, A. (1970). Sanity, Madness and the Family. London: Basic Books.

Larkin, W., \& Morrison, A. (Eds.) (2006). Trauma and Psychosis: New Directions for Theory and Therapy. London: Routledge.

Levy, K. N. (2005). The implications of attachment theory and research for understanding borderline personality disorder. Development and Psychopathology, 17: 959-986.

Lewis, G., David, A., Andreassen, S., \& Allebeck, P. (1992). Schizophrenia and city life. Lancet, 340: 137-140. 
Liotti, G. (1992). Disorganized/disoriented attachment in the etiology of the dissociative disorders. Dissociation, 5: 196-204.

Liotti, G. (2004). Trauma, dissociation and disorganized attachment: Three strands of a single braid. Psychotherapy: Theory, Research, Practice, Training, 41: 472-486.

Liotti, G. (2006). A model of dissociation based on attachment theory and research. Journal of Trauma and Dissociation, 7: 55-74.

Liotti, G., Pasquini, P., \& The Italian Group for the Study of Dissociation (2000). Predictive factors for borderline personality disorder: patients' early traumatic experiences and losses suffered by the attachment figure. Acta Psychiatrica Scandinavica, 102: 282-289.

Liotti G., \& Gumley, A. (in press). An attachment perspective on schizophrenia: disorganized attachment, dissociative processes, and compromised mentalisation. In: A. Moscowitz, M. Dorahy, \& I. Schaefer (Eds.), Dissociation and Psychosis: Converging Perspectives on a Complex Relationship. Hoboken, New Jersey: Wiley.

Lyons-Ruth, K., Yellin, C., Melnick, S., \& Atwood, G. (2003). Childhood experiences of trauma and loss have different relations to maternal unresolved and hostile-helpless states of mind on the AAI. Attachment and Human Development, 5: 330-352.

Macbeth, A., Schwannauer, M., \& Gumley, A. (in press). Attachment style, social mentalities and paranoid ideation: an analogue study. Psychology and Psychotherapy: Theory Research and Practice.

Main, M. (1991). Metacognitive knowledge, metacognitive monitoring, and singular (coherent) versus multiple (incoherent) models of attachment. In: C. Parkes, J. Stevenson-Hinde, \& P. Marris (Eds.), Attachment Across the Life Cycle (pp. 127-160). London: Routledge.

Main, M. (1995). Recent studies in attachment: overview, with selected implications for clinical work. In: S. Goldberg, R. Muir, \& J. Kerr (Eds.), Attachment Theory: Social, Developmental and Clinical Perspectives (pp. 407-474).Hillsdale, NJ: Analytic Press.

Main, M., \& Hesse, E. (1990). Parents' unresolved traumatic experiences are related to infant disorganized attachment status: is frightened and/or frightening parental behaviour the linking mechanism? In: M. Greenberg, D. Cicchetti, \& E. Cummings (Eds), Attachment in the Preschool Years (pp. 161-182). New York: Plenum.

Mallett, R., Leff, J., Bhugra, D., Pang, D., \& Zhao, J. (2002). Social environment, ethnicity and schizophrenia. Social Psychiatry \& Psychiatric Epidemiology, 37: 329-335.

Malmberg, A., Lewis, G., David, A., \& Allebeck, P. (1998). Premorbid adjustment and personality in people with schizophrenia. British Journal of Psychiatry, 172: 308-313.

Marcus, J., Hans, S., Nagler, S., Auerbach, J., Mirsky, A., \& Aubrey, A. (1987). Review of the NIMH Israeli Kibbutz-City Study and the Jerusalem Infant Development Study. Schizophrenia Bulletin, 13: 425-438.

Marjoram, D., Miller, P., McIntosh, A., Cunningham Owens, D., Johnstone, E., \& Lawrie, S. (2006). A neuropsychological investigation into 'Theory of Mind' and enhanced risk of schizophrenia. Psychiatry Research, 144: 29-37.

Mason, O., Startup, M., Halpin, S., Schall, U., Conrad, A., \& Carr, V. (2004). Risk factors for transition to first episode psychosis among individuals with 'at risk mental states'. Schizophrenia Research, 71: 227-237.

Can Attachment Theory Help Explain the Relationship Between Childhood Adversity and Psychosis? 
McCreadie, R., Williamson, D., Athawes, R., Connolly, M., \& Tilak-Singh, D. (1994). The Nithsdale Schizophrenia Surveys XIII: Parental rearing patterns, current symptomatology and relatives' expressed emotion. British Journal of Psychiatry, 165: 347-352.

Myhrman, A., Rantakallio, P., Isohanni, K., Jones, P., \& Partanen, U. (1996). Unwantedness of a pregnancy and schizophrenia in the child. British Journal of Psychiatry, 169: 637-640.

Mickelson, K., Kessler, R., \& Shaver, P. (1997). Adult attachment in a nationally representative sample. Journal of Personality and Social Psychology, 73: 1092-1106.

Miti, G., \& Chiaia, E. (2003). Patterns of attachment and the etiology of dissociative disorders and borderline personality disorder. Journal of Trauma Practice, 2: 19-35.

Morgan, C., Kirkbride, J., Leff, J., Craig, T., Hutchinson, G., McKenzie, K., Morgan, K., Dazzan, P., Doody, G., Jones, P., Murray R., \& Fearon, P. (2007). Parental separation, loss and psychosis in different ethnic groups: a case-control study. Psychological Medicine, 37: 495-503.

Morrison, A., \& Petersen, T. (2003). Trauma and metacognition as predictors of predisposition to hallucinations. Behavioural and Cognitive Psychotherapy, 31: 235-246.

Mosher, L., Gosden, R., \& Beder, S. (2004). Drug companies and schizophrenia: unbridled capitalism meets madness. In: J. Read, L. Mosher, \& R. Bentall (Eds.), Models of Madness (pp. 116-130). London: Routledge.

Moskowitz, A., Read, J., Farrelly, S., Rudegeair, T., \& Williams. O. (in press). Are psychotic symptoms traumatic in origin and dissociative in kind? In: P. Dell \& J. O'Neils (Eds.), Dissociation and the Dissociative Disorders: DSM V and Beyond. London: Routledge.

Mullen, P., Martin, J., Anderson, J., Romans, S., \& Herbison, G. (1996). The long-term impact of the physical, emotional and sexual abuse of children: a community study. Child Abuse \& Neglect, 20: 7-21.

Murphy, J., Shevlin, M., \& Adamson, G. (2007). A latent class analysis of positive psychosis symptoms based on the British Psychiatric Morbidity Survey. Personality and Individual Differences, 42: 1491-1502

Ogawa, J., Sroufe, L., Weinfield, N., Carlson, E., \& Egeland, B. (1997). Development and the fragmented self: longitudinal study of dissociative symptomatology in a nonclinical sample. Development and Psychopathology, 9: 855-879.

Onstad, S., Skre, I., Torgersen, S., \& Kringlen, E. (1994). Family interaction: parental representation in schizophrenic patients. Acta Psychiatrica Scandinavica, 90 (suppl 384): 67-70.

Parker, G. (1983). Parental Overprotection: A Risk Factor in Psychosocial Development. New York: Grune \& Stratton.

Parker, G., Fairley, M., Greenwood, J., Jurd, S., \& Silove, D. (1982). Parental representation of schizophrenics and their association with onset and course of schizophrenia. British Journal of Psychiatry, 141: 573-581.

Parker, G., Hayward, L., \& Johnston, P. (1989). Factorial validity of the EE scales. Psychological Medicine, 19: 435-446. 
Parker, G., Tupling, H., \& Brown, L. (1979). A parental bonding instrument. British Journal of Medical Psychology, 52: 1-10.

Parnas, J., Teasdale, T., \& Schulsinger, H. (1985). Institutional rearing and diagnostic outcome in children of schizophrenic mothers: a prospective high-risk study. Archives of General Psychiatry, 42: 762-769.

Pasquini, P., Liotti, G., Mazzotti, E., Fassone, G., Picardi, A., \& The Italian Group for the Study of Dissociation (2002). Risk factors in the early family life of patients suffering from dissociative disorders. Acta Psychiatrica Scandinavica, 105: $110-116$.

Pedersen, C., \& Mortenson, P. (2001). Evidence of a dose-response relationship between urbanicity during upbringing and schizophrenia risk. Archives of General Psychiatry, 58: 1039-1046.

Pickering, L., Simpson, J., \& Bentall, R. (in press). Insecure attachment predicts proneness to paranoia but not hallucinations. Personality and Individual Differences.

Pickup, G. (2006). Theory of mind and its relation to schizotypy. Cognitive Neuropsychiatry, 11(2): 177-192

Ponizovsky, A., Nechamkin, Y., \& Rosca, P. (2007). Attachment patterns are associated with symptomatology and course of schizophrenia in male inpatients. American Journal of Orthopsychiatry, 77: 324-331.

Rankin, P., Bentall, R., Hill, J., \& Kinderman, P. (2005). Perceived relationships with parents and paranoid delusions: comparisons of currently ill, remitted and normal participants. Psychopathology, 38: 16-25.

Read, J. (2004a). The invention of 'schizophrenia'. In: J. Read, L. Mosher, \& R. Bentall (Eds.), Models of Madness (pp. 21-34). London: Routledge.

Read, J. (2004b). Poverty, ethnicity and gender. In: J. Read, L. Mosher, \& R. Bentall (Eds.), Models of Madness (pp. 161-194). London: Routledge.

Read, J. (2006). Breaking the silence: learning why, when and how to ask about trauma, and how to respond to disclosures. In: W. Larkin \& A. Morrison(Eds.), Trauma and Psychosis (pp. 195-221). London: Routledge.

Read, J. (2007). Why promulgating biological ideology increases prejudice against people labelled 'schizophrenic'. Australian Psychologist, 42: 118-128.

Read, J. (2008). Schizophrenia, drug companies and the internet. Social Science \& Medicine, 66: 99-109.

Read, J., \& Hammersley, P. (2006). Can very bad childhoods drive us crazy? Science, ideology and taboo. In: J. Johannessen, B. Martindale, \& J. Cullberg (Eds.), Evolving psychosis: Different stages, Different Treatments, (pp. 270-292). London: Routledge.

Read, J., Agar, K., Argyle, N., \& Aderhold, V. (2003). Sexual and physical assault during childhood and adulthood as predictors of hallucinations, delusions and thought disorder. Psychology and Psychotherapy: Theory, Research and Practice, 76: 1-22.

Read, J., Goodman, L., Morrison, A., Ross, C., \& Aderhold, V. (2004). Childhood trauma, loss and stress. In: J. Read, L. Mosher, \& R. Bentall (Eds.), Models of Madness (pp. 223-252). London: Routledge.

Read, J., Hammersley, P., \& Rudegeair, T. (2007). Why, when and how to ask about child abuse. Advances in Psychiatric Treatment, 13: 101-110. 
Read, J., Haslam, N., Sayce, L., \& Davies, E. (2006). Prejudice and schizophrenia: a review of the 'mental illness is an illness like any other' approach. Acta Psychiatrica Scandinavica, 114: 303-318.

Read, J., Mosher, L., \& Bentall, R. (Eds) (2004). Models of Madness: Psychological, Social and Biological Approaches to Schizophrenia. London: Routledge.

Read, J., Mosher, L., \& Seymour, F. (2004). Unhappy families. In: J. Read, L. Mosher, \& R. Bentall (Eds.), Models of Madness (pp. 253-268). London: Routledge.

Read, J., Perry, B., Moskowitz, A., \& Connolly, J. (2001). The contribution of early traumatic events to schizophrenia in some patients: a traumagenic neurodevelopmental model. Psychiatry, 64: 319-345.

Read, J., van Os, J., Morrison, A., \& Ross, C. (2005). Childhood trauma, psychosis and schizophrenia: a literature review with theoretical and clinical implications. Acta Psychiatrica Scandinavica, 112: 330-350.

Robins, L. (1966). Deviant Children Growing Up. London: Williams Wilkins.

Roff, J., \& Knight, R. (1981). Family characteristics, childhood symptoms, and adult outcome in schizophrenia. Journal of Abnormal Psychology, 90: 510-520.

Romme, M., \& Escher, S. (2006). Trauma and hearing voices. In: W. Larkin \& A. Morrison (Eds.), Trauma and Psychosis (pp. 162-191). London: Routledge.

Ross, C. (2004). Schizophrenia: Innovations in Diagnosis and Treatment. Binghamton, NY: Haworth.

Ross, C., Anderson, G., \& Clark, P. (1994). Childhood abuse and positive symptoms of schizophrenia. Hospital and Community Psychiatry, 45: 489-491.

Schafer, I., Harfst, T., Aderhold, V., Briken, P., Lehmann, M., Moritz, S., Read, J., \& Naber, D. (2006). Childhood trauma and dissociation in female patients with schizophrenia spectrum disorders: an exploratory study. Journal of Nervous \& Mental Disease, 194: 135-138.

Schiffman, J., Abrahamson, A., Cannon, T., LaBrie, J., Parnas, J., Schulsinger, F., \& Mednick, S. (2001). Early rearing factors in schizophrenia. International Journal of Mental Health, 30: 3-16.

Schiffman, J., LaBrie, J., Carter, J., Tyrone, C., Schulsinger, F., Parnas, J., \& Mednick, S. (2002). Perception of parent-child relationships in high-risk families, and adult schizophrenia outcome of offspring. Journal of Psychiatric Research, 36: 41-47.

Schiffman, J., Lam, C., Jiwatram, T., Ekstrom, M., Sorensen, H., \& Mednick, S. (2004). Perspective-taking deficits in people with schizophrenia: A prospective investigation. Psychological Medicine, 34: 1581-1586.

Schore, A. (2003). Affect Dysregulation and the Disorders of the Self. New York: Norton.

Schuengel, C., Bakermans-Kranenburg, M., van Ijzendoorn, M., \& Blom, M. (1999). Unresolved loss and infant disorganization: links to frightening maternal behavior. In: J. Solomon \& C. George (Eds.), Attachment Disorganization. New York: Guilford.

Seedat, S., Stein, M., Oosthuizen, P., Emsley, R., \& Stein, D. (2003). Linking posttraumatic stress disorder and psychosis: a look at epidemiology, phenomenology, and treatment. Journal of Nervous and Mental Disease, 191: 675-681.

Shevlin, M., Dorahy, M., \& Adamson, G. (2007a). Childhood traumas and hallucinations: an analysis of the National Comorbidity Survey. Journal of Psychiatric Research, 41: 222-228. 
Shevlin, M., Dorahy, M., \& Adamson, G. (2007b). Trauma and psychosis: an analysis of the National Comorbidity Survey. American Journal of Psychiatry, 164; 166-169.

Spence, W., Mulholland, C., Lynch, G., McHugh, S., Dempster, M., \& Shannon, C. (2006). Rates of childhood trauma in a sample of patients with schizophrenia compared with a sample of patients with non-psychotic psychiatric diagnoses. Journal of Trauma \& Dissociation, 7: 7-22.

Sprong, M., Schothorst, P., Vos, E., Hox, J., \& van Engeland, H. (2007). Theory of mind in schizophrenia: meta-analysis. British Journal of Psychiatry, 191: 5-13.

Sullivan, H. (1962). Schizophrenia as a Human Process. New York: Norton.

Tienari, P. (1991). Interaction between genetic vulnerability and family environment: the Finnish adoptive family study of schizophrenia. Acta Psychiatrica Scandinavica, 84: $460-465$.

van Ijzendoorn, M., Schuengel, C., \& Bakermans-Kranenburg, M. (1999). Disorganized attachment in early childhood: meta-analysis of precursors, concomitants and sequelae. Development and Psychopathology, 11: 225-250.

Vaughn, C., \& Leff, J. (1976). The influence of family and social factors on the course of psychiatric illness. British Journal of Psychiatry, 129: 125-137.

Walsh, F. (1978). Concurrent grandparent death and birth of schizophrenic offspring: An intriguing finding. Family Process, 17: 457-463.

Warner, R., \& Atkinson, M. (1988). The relationship between schizophrenics' perceptions of their parents and the course of their illness. British Journal of Psychiatry, 153: 344-353.

Waters, E., Merrick, S., Treboux, D., Crowell, J., \& Albersheim, L. (2000). Attachment security in infancy and early adulthood: a 20-year longitudinal study. Child Development, 71: 684-689.

Watt, N., \& Nicholi, A. (1979). Early death of a parent as an etiological factor in schizophrenia. American Journal of Orthopsychiatry, 49: 465-473.

Whitfield, C., Dube, S., Felitti, V., \& Andra, R. (2005). Adverse childhood experiences and hallucinations. Child Abuse \& Neglect, 29: 797-810

Willinger, U., Heiden, A., Meszaros, K., Formann, A., \& Aschauer, H. (2002). Maternal bonding behaviour in schizophrenia and schizoaffective disorder, considering premorbid personality traits. Australian and New Zealand Journal of Psychiatry, 36: 663-668.

Wilson, J., \& Costanzo, P. (1996). A preliminary study of attachment, attention, and schizotypy in early adulthood. Journal of Social and Clinical Psychology, 15: 231-260.

Winther Helgeland, M., \& Torgersen, S. (1997). Maternal representation of patients with schizophrenia as measured by the parental bonding instrument. Scandinavian Journal of Psychology, 38: 39-43.

Zubin, J., \& Spring, B. (1997). Vulnerability: a new view of schizophrenia. Journal of Abnormal Psychology, 86: 103-126.

Can Attachment Theory Help Explain the Relationship Between Childhood Adversity and Psychosis? 